\title{
Vitamin D Deficiency in Critically Ill Children with Sepsis: What is the Road ahead?
}

\author{
Rajakumar Padur Sivaraman 1 \\ Indian Journal of Critical Care Medicine (2021): 10.5005/jp-journals-10071-23952
}

Vitamin D acts as a steroid hormone with myriad functions in addition to the role in bone mineral metabolism. Vitamin D receptors are present in several tissues including immune system, cardiovascular system, and endocrine system. ${ }^{1}$ Hence, the possible role of vitamin D deficiency (VDD) in illness outside of bone mineral metabolism has been the subject of active research for the last two decades.

From the time the first observational study on VDD in critically ill adults was published in 2009 by Lee et al, research in adult critical care has progressed in a frantic pace with several studies including meta-analysis confirming that VDD in critically ill adults is associated with worse outcomes including mortality, length of hospital stay, and need for vasopressors. ${ }^{2,3}$ This was followed by intervention studies to check whether vitamin D supplementation in critically ill adults with VDD early in the course results in better outcomes. VITdAL-ICU trial by Amrein et al. published in 2014 failed to show any benefit in outcomes in early supplementation with vitamin D enterally in critically ill adults with $25 \mathrm{OH}$ D levels $\leq 20 \mathrm{ng} / \mathrm{mL}$ compared to placebo. ${ }^{4}$ However, subgroup analysis showed a decrease in mortality in the group with severe VDD $\leq 12 \mathrm{ng} / \mathrm{mL}$. Though the study was underpowered for subgroup analysis, it raised the hope that a subset of patients with severe VDD might benefit from early vitamin D supplementation. However, a much larger, multicenter randomized controlled trial (RCT) (VIOLET) by PETAL study group published in 2019 failed to show any difference in mortality or other clinically relevant outcomes between those who received vitamin $D$ supplementation and those who did not, including the subgroup with severe VDD. ${ }^{5}$ The latest meta-analysis on the topic published in 2020 concluded that more studies are needed to confirm the futility of vitamin D supplementation as there was significant heterogeneity in the clinical characteristics of patients in the studies analyzed. ${ }^{6}$ Given the fact that VDD is related to inflammation and immune dysfunction, critically ill patients with sepsis and VDD might be the subgroup which could benefit from early supplementation with vitamin D. Meta-analysis published in 2020 on VDD and risk of mortality in adults with sepsis recommended that large clinical trials with adequate sample size for patients with severe VDD (level $<12 \mathrm{ng} / \mathrm{mL}$ ) are needed to evaluate the potential benefits of vitamin D supplementation in patients with critical illnesses and sepsis. ${ }^{7}$

The progress of research in VDD and outcomes in critically ill children is rather slow compared to the adult critical care. Though the first observational study on high prevalence of VDD in critically ill children was published in 2012, subsequent studies, especially the ones from developing countries, have shown inconsistent results on the association between VDD and outcomes like mortality and length of hospital stay. ${ }^{8-10}$ This could be due to small sample size, different tests used in analysis of vitamin D levels, different cutoff used for VDD, and the effect of critical illness on vitamin D level
Department of Pediatrics, Sri Ramachandra Institute of Higher Education and Research (SRIHER), Chennai, Tamil Nadu, India

Corresponding Author: Rajakumar Padur Sivaraman, Department of Pediatrics, Sri Ramachandra Institute of Higher Education and Research (SRIHER), Chennai, Tamil Nadu, India, Phone: +91-4445928652, e-mail: rajakumar.ps@sriramachandra.edu.in

How to cite this article: Sivaraman RP. Vitamin D Deficiency in Critically III Children with Sepsis: What is the Road ahead? Indian J Crit Care Med 2021;25(8):843-844.

Source of support: Nil

Conflict of interest: None

like hemodilution and hypoalbuminemia. The gold standard tests for estimating the level of $25(\mathrm{OH}) \mathrm{D}$ namely high-performance liquid chromatography and liquid chromatography-tandem mass spectrometry are not available in most centers. The first systematic review of pediatric studies done in 2016 concluded that VDD in critically ill children was associated with worse outcomes including mortality after the data from the studies were pooled. ${ }^{11}$

In this issue of our journal, Ravikiran et al. report the findings of their case-control study on hypovitaminosis D [25(OH)D $<30 \mathrm{ng} / \mathrm{mL}$ ] and parathormone (PTH) response in critically ill children with sepsis. This is an important area of research as sepsis is one of the most common reasons for pediatric intensive care unit (PICU) admission in developing countries and there is paucity of studies in this area. The authors report prevalence of hypovitaminosis $D$ $[25(\mathrm{OH}) \mathrm{D}<30 \mathrm{ng} / \mathrm{mL}$ ] to be $79.7 \%$, with vitamin $\mathrm{D}$ insufficiency $[25(\mathrm{OH}) \mathrm{D}=21-29.9 \mathrm{ng} / \mathrm{mL}]$ to be $59.5 \%$, and VDD $[25(\mathrm{OH}) \mathrm{D} \leq 20 \mathrm{ng} /$ $\mathrm{mL}$ ] to be $20.2 \%$, which is less compared to studies from the north India. This could be because of geographical differences in altitude and latitude, dietary differences, vitamin D level estimation methods used, and differences in underlying diseases.

The authors of the current study did not find any statistically significant association between hypovitaminosis D and worse PICU outcomes namely mortality and PICU stay. This is similar to the study by Ponnarmeni et al. from a tertiary center in North India published in 2016. ${ }^{9}$ Recent studies from a tertiary center in South India by Kumar et al. in 2020 showed a significantly higher prevalence of sepsis in critically ill children with VDD. However, mortality was not associated with VDD in multilogistic regression analysis. ${ }^{12}$ There could be several reasons for the lack of association of VDD with worse outcomes in the current study. First, the sample size of the study was too small for subgroup analysis on outcomes as discussed by the authors. Second, the cutoff value of vitamin D level selected for analysis was $25(\mathrm{OH}) \mathrm{D}<30 \mathrm{ng} / \mathrm{mL}$ in the study rather than $<20 \mathrm{ng} / \mathrm{mL}$ used by most studies in the past. The

(0) Jaypee Brothers Medical Publishers. 2021 Open Access This article is distributed under the terms of the Creative Commons Attribution 4.0 International License (https://creativecommons.org/licenses/by-nc/4.0/), which permits unrestricted use, distribution, and non-commercial reproduction in any medium, provided you give appropriate credit to the original author(s) and the source, provide a link to the Creative Commons license, and indicate if changes were made. The Creative Commons Public Domain Dedication waiver (http://creativecommons.org/publicdomain/zero/1.0/) applies to the data made available in this article, unless otherwise stated. 
authors justify the higher cutoff based on the inflection point in PTH curve from linear to plateau at $30 \mathrm{ng} / \mathrm{mL}$ level. However, PTH response $(>65 \mathrm{pg} / \mathrm{mL}$ ) was found in only $13.8 \%$ of children with levels $<30 \mathrm{ng} / \mathrm{mL}$ in this study. Earlier study by Shah et al. in 2016 showed a PTH response (PTH $>65 \mathrm{pg} / \mathrm{mL}$ ) rate of $19.5 \%$ using a cutoff of $25(\mathrm{OH}) \mathrm{D}<20 \mathrm{ng} / \mathrm{mL} .{ }^{10}$ Both the studies did not find any association between PTH nonresponse and adverse outcomes in those with VDD. The number of children for this subgroup analysis was again too small for any meaningful conclusion.

Recent RCT published in 2020 showed that the administration of 150,000 IU of vitamin D in children with sepsis and VDD $(\leq 20 \mathrm{ng} / \mathrm{mL})$ resulted in lower IL-6, TNF a level, cv-SOFA score, and lower incidence of septic shock compared to those who received placebo. ${ }^{13}$ This has opened the possibility of intervention studies in critically ill children with sepsis who have VDD. Lessons learnt from past studies including adult studies in this area can be useful while planning future studies in children. First, large dose of vitamin D should be administered enterally early for its effects to kick in for a meaningful outcome. Second, supplementation is likely to be beneficial in children with severe VDD $<12 \mathrm{ng} / \mathrm{mL}$. The sample size should be adequate to give sufficient power to analyze outcomes in this subgroup of children as well as for adjustments for confounding factors. Third, given the low mortality rate in critically ill children, length of hospital stay would be a better primary outcome measure. Fourth, measurements of 25(OH)D and 1, $25(\mathrm{OH}) 2 \mathrm{D}$ levels 48 hours after administration of vitamin D will help to understand predictors of favorable outcome. Researchers will have to balance the robustness of the methodology with feasibility in planning such a study. Till then, the question whether VDD in critical illness is an innocent bystander or an attributable risk factor for adverse outcome which is amenable for intervention will continue to remain in critical care. ${ }^{14}$

\section{ORCID}

Rajakumar Padur Sivaraman (ㄱ) https://orcid.org/0000-0002-91299786

\section{References}

1. Zittermann A, Gummert JF. Nonclassical vitamin D action. Nutrients 2010;2(4):408-425. DOI: 10.3390/nu2040408.
2. Lee $P$, Eisman JA, Center JR. Vitamin D deficiency in critically ill patients. N Engl J Med 2009;360(18):1912-1914. DOI: 10.1056/ NEJMc0809996.

3. Zhang YP, Wan YD, Sun TW, Kan QC, Wang LX. Association between vitamin $D$ deficiency and mortality in critically ill adult patients: a meta-analysis of cohort studies. Crit Care 2014;18:684. DOI: 10.1186/ s13054-014-0684-9.

4. Amrein K, Schnedl C, Holl A, Riedl R, Christopher KB, Pachler C, et al. Effect of high-dose vitamin D3 on hospital length of stay in critically ill patients with vitamin D deficiency: the VITdAL-ICU randomized clinical trial. JAMA 2014;312:1520-1530. DOI: 10.1001/jama.2014.13204.

5. Ginde A, Brower RG, Caterino JM, Finck L, Banner-Goodspeed VM, Grissom CK, et al. Early high-dose vitamin D3 for critically ill, vitamin D-deficient patients. N Engl J Med 2019;381(26):2529-2540. DOI: 10.1056/NEJMoa1911124.

6. Lan S, Lai C, Chang S, Lu L, Hung S, Lin W. Vitamin D supplementation and the outcomes of critically ill adult patients: a systematic review and meta-analysis of randomized controlled trials. Sci Rep 2020;10:14261. DOI: 10.1038/s41598-020-71271-9.

7. Li Y, Ding S. Serum 25 -hydroxyvitamin D and the risk of mortality in adult patients with sepsis: a meta-analysis. BMC Infect Dis 2020;20(1):189. DOI: 10.1186/s12879-020-4879-1.

8. McNally JD, Menon K, Chakraborty P, Fisher L, Williams AK, Al-Dirbashi OY, et al. The association of vitamin $\mathrm{D}$ status with pediatric critical illness. Pediatrics 2012;130(3):429-436. DOI: 10.1542/peds.20113059.

9. Ponnarmeni S, Angurana SK, Singhi S, Bansal A, Dayal D, Kaur R, et al. Vitamin D deficiency in critically ill children with sepsis. Paediatr Int Child Health 2016;36(1):15-21. DOI: 10.1179/2046905515Y.0000000042.

10. Shah SK, Kabra SK, Gupta N, Pai G, Lodha R. Vitamin D deficiency and parathyroid response in critically-ill children: association with illness severity and clinical outcomes. Indian Pediatr 2016;53(6):479-484. DOI: 10.1007/s13312-016-0876-2.

11. McNally JD, Nama N, O'Hearn K, Sampson M, Amrein K, liriani K, et al. Vitamin $D$ deficiency in critically ill children: a systematic review and meta-analysis. Crit Care 2017;21(1):287. DOI: 10.1186/s13054-017-1875-y.

12. Kumar MK, Das S, Biswal N, Parameswaran N, Nanda N. Vitamin D status at admission and its association with mortality in children admitted to the pediatric intensive care unit. Cureus 2020;12(6):e8413. DOI: 10.7759/cureus.8413.

13. Wang Y, Yang Z, Gao L, Cao Z, Wang Q. Effects of a single dose of vitamin $D$ in septic children: a randomized, double-blinded, controlled trial. J Int Med Res 2020;48(5);1-11. DOI: 10.1177/0300060520926890.

14. Kubsad P, Ravikiran SR, Bhat KG, Kamath N, Kulkarni V, Manjrekar PA, et al. Hypovitaminosis D and Parathyroid Hormone Response in Critically III Children with Sepsis: A Case-control Study. Indian J Crit Care Med 2021;25(8):917-921. 